\title{
Epidemiology of Cleft Lip and Palate
}

\author{
Mairaj K. Ahmed, Anthony H. Bui and \\ Emanuela Taioli \\ Additional information is available at the end of the chapter
}

http://dx.doi.org/10.5772/67165

\begin{abstract}
Orofacial cleft (OFC) anomalies are amongst the most common congenital anomalies and the most common craniofacial anomalies. Despite their poorly characterized etiologies, cases of OFC are usually grouped by epidemiological studies as cleft lip, with or without cleft palate $(\mathrm{CL} / \mathrm{P})$, and cleft palate alone (CPO). Incidence of $\mathrm{CL} / \mathrm{P}$ and $\mathrm{CPO}$ differs according to gender and ancestry and may vary widely across studies. Cases of OFC are characterized as either "syndromic" or "nonsyndromic," with further classification of nonsyndromic cases into isolated cases and cases that present with additional malformations. The genetic bases for many syndromic cases of OFC have been previously elucidated. Genetic associations have been described for nonsyndromic OFC as well. Importantly, etiology of OFC is known to involve interaction between genetic and environmental factors, including maternal nutrition and exposure to teratogenic agents. Furthermore, evidence points toward epigenetic as well as genetic factors influencing OFC etiology. Recent studies have begun to explore the association between CL/P and cancer. These studies report higher incidence of cancer among patients with $\mathrm{CL} / \mathrm{P}$ and their family members as well as identification of common genetic markers mediating this increased risk, although much remains unknown about this link.
\end{abstract}

Keywords: cleft, epidemiology, etiology, genetics, epigenetics, environmental risk factors, cancer

\section{Introduction}

Orofacial cleft (OFC) anomalies may be unilateral or bilateral and involve the lip, the palate, or both. Due to similar phenotypic overlap and resulting health care needs of these patients, epidemiological studies usually group cleft lip, with or without cleft palate (CL/P), and cleft 
palate alone (CPO) even though the etiology of each may be unique. Whether or not CL/P and $\mathrm{CPO}$ have distinct etiology and should be combined in investigations is under debate.

It is often found in epidemiological studies that $\mathrm{CL} / \mathrm{P}$ and $\mathrm{CPO}$ is considered underneath the umbrella of either "syndromic" or "nonsyndromic." Furthermore, "nonsyndromic" CL/P and $\mathrm{CPO}$ cases can be subgrouped into those that are isolated or those that have additional malformations that do not form a recognizable syndrome. Relatively, the etiology of nonsyndromic cases of $\mathrm{CL} / \mathrm{P}$ and $\mathrm{CPO}$ is lesser known compared to those found identified with a syndrome. Due to the poorly characterized etiology of $\mathrm{CL} / \mathrm{P}$ and $\mathrm{CPO}$, in general, there is still debate for the best method of grouping CL/P and CPO in epidemiological studies, but the most common current classifications are used to help determine associations and thus help the clinician with their diagnosis and subsequent treatment.

The genetic basis for many syndromic cases of CL/P and CPO are well-described. Evidence for genetic factors underlying nonsyndromic $\mathrm{CL} / \mathrm{P}$ and $\mathrm{CPO}$ has begun to materialize as well. While less well-described, it is also known that epigenetic modifications can play a role in the development of CL/P and CPO. Recently, the association between OFC and cancer has been explored, with evidence suggesting existence of a link between the presence of OFC in patients and risk of cancer in these patients and/or their families.

\section{Descriptive epidemiology}

\subsection{Prevalence}

The overall prevalence of OFC is estimated to be approximately 1 in 700 live births, accounting for nearly one half of all craniofacial anomalies [1, 2]. As reported by the World Health Organization (WHO), the prevalence at birth of OFC varies worldwide, ranging 3.4-22.9 per 10,000 births for CL/P, and 1.3-25.3 per 10,000 births for CPO [3]. The incidence of CL/P and $\mathrm{CPO}$ can vary greatly between studies. The inclusion criteria, case definition, data sources, and selection bias contribute to the varying incidence estimates. Even though there are many different variables regarding the inclusion or exclusion criteria of in studies, the majority report a higher incidence of CL/P compared to CPO.

Prevalence has been found to vary based on ancestry, with the highest incidence rates observed amongst Asian populations (0.82-4.04 per 1000 live births), intermediate rates amongst Caucasians (0.9-2.69 per 1000 live births), and the lowest rates amongst African populations (0.18-1.67 per 1000 live births) [1, 4]. Prevalence has also been found to vary further by subgroup, for example, with one study reporting lower rates of OFC amongst Far East Asians compared to Filipinos [5].

\subsection{Gender ratio}

Prevalence of OFC additionally varies according to gender and cleft pattern. Male predominance has been consistently identified in CLP, with a male/female sex ratio of 1.81 (CI 95\%: 
1.75-1.86). For $\mathrm{CP}$, the opposite has been shown, with a reported sex ratio of 0.93 (CI 95\%: 0.89-0.96) [3]; however, this may be due in part to sampling bias, as one Danish study could not find a significant predominance of females in individuals with $\mathrm{CP}$ after combining both surgically treated and nonsurgically treated cases [6].

\subsection{Laterality}

OFC may be unilateral or bilateral. According to the International Perinatal Database of Typical Orofacial Clefts (IPDTOC) working group, the proportion of bilateral cases is $10.3 \%$ for cleft lip without palate (CL) and 30.2\% for cleft lip with palate (CLP). Amongst unilateral cases, $36.9 \%$ of CL and $41.1 \%$ of CLP occur on the right side, suggesting that unilateral cases of CL/P occur more frequently on the left [7].

\section{Classification}

It is often found in epidemiological studies that CL/P and CPO are classified as either "syndromic" or "nonsyndromic." Cases of "nonsyndromic" CL/P and CPO are further categorized as isolated - those without an underlying syndrome or additional, nonsecondary malformations - or multiple - those that have additional malformations that do not form a recognizable syndrome. These distinctions are important epidemiologically, for identifying homogenous subgroups of cases, and clinically, for informing prognosis, recurrence risk, diagnosis, and treatment plan.

\subsection{Syndromic}

Individuals with "syndromic" CL/P or CP present with patterns of malformations and/or symptomatology that form a recognizable syndrome of known or unknown origin; hence, the $\mathrm{CL} / \mathrm{P}$ or $\mathrm{CP}$ is part of a syndrome. Recognition of these syndromes is essential for assessing the risks faced by the child, providing the necessary treatment, and counseling the parents. Because the prevalence of associated anomalies varies across different populations of individuals with OFC, better understanding of the epidemiology of these anomalies could aid in the proper identification and characterization of the syndrome, leading to better care for the individual. Syndromes associated with OFC for which the underlying cause is known include chromosomal abnormalities, such as trisomy 13 or 18, Mendelian disorders such as Van der Woude Syndrome and teratogenic exposure.

A guideline for identifying syndromes in individuals with CL/P or CP is outlined by Venkatesh as follows [8]:

- Thorough clinical examination, preferably by geneticist or dysmorphologist.

- Comprehensive medical history: description of the cleft, antenatal history, birth history, developmental history, and family history. 
- Physical examination: measurement of weight, length or height, and occipitofrontal circumference, identification of anomalies of eyes, ears, heart, extremities, and also to look for associated preauricular tags, lip pits, and epicanthal folds.

- Documentation by photographs of all affected individuals and first-degree relatives.

- Necessary laboratory and radiological evaluations.

\subsection{Multiple}

The multiple subset of $\mathrm{CL} / \mathrm{P}$ and $\mathrm{CPO}$ includes those cases that are not a part of a recognizable syndrome and have major other malformations which may involve, but are not limited to, the eye, ear, head, neck, respiratory tract, gastrointestinal tract, and musculoskeletal system $[5,9]$. Cases of "multiple nonsyndromic" CL/P and CPO may be classified as such simply by virtue of unrecognized syndromes or undocumented teratogenic exposures. Furthermore, wide variation exists in the classification of associated anomalies in cases of OFC [10].

\subsection{Isolated}

Cases of CL/P and CPO that are classified as "isolated" do not have an underlying syndrome or other secondary malformations. Most epidemiological studies of CL/P and CPO focus on those cases that are isolated in hopes to further gain insight into associations.

\section{Etiology}

Development of the head and face represents one of the most intricate events during embryonic development, synchronized by a network of transcription factors and signaling molecules together with proteins conferring cell polarity and cell-cell interactions. In mammals, the facial region develops from the facial primordia, which consists of the lateral and medial nasal prominences arising from the frontonasal process and the maxillary and mandibular processes arising from the first branchial arch. As demonstrated in Figure 1, fusion of medial nasal and maxillary prominences gives rise to the lip and primary palate, while fusion of separate palatal processes arising from the maxillary prominence gives rise to the secondary palate and occurs later during embryogenesis. These processes are known to be dependent, in part, on the migration and differentiation of neural crest cells from the neuroectoderm into the branchial arches [11].

Disturbance of this closely controlled cascade can result in a facial cleft where these facial primordia ultimately fail to meet and fuse or form the proper structures. Historically, OFCs have been classified as either CL/P or CPO $[13,14]$. This broad subdivision is consistent with both the distinct developmental origins of the lip/primary palate and the secondary palate and the distinct cellular and genetic etiologies described for CL/P and CPO; cleft palate may occur secondary to or independently from cleft lip. However, there is some epidemiologic 
evidence suggesting that cleft lip only has distinct etiologic features from cleft lip with palate and should be classified accordingly $[15,16]$.

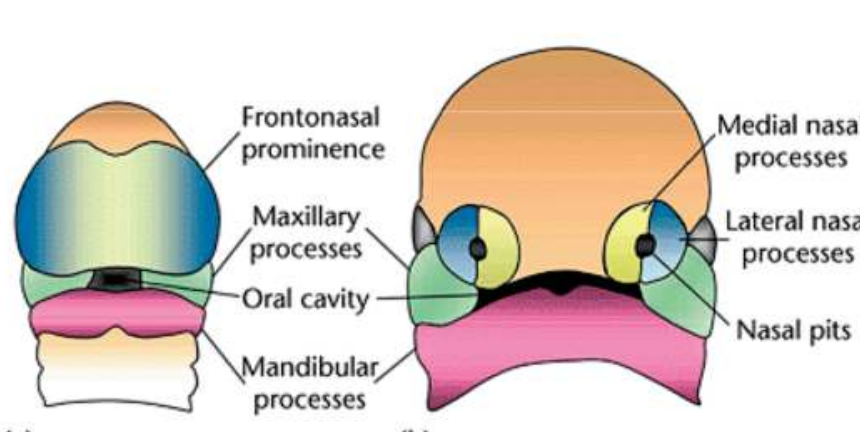

(a)

(b)

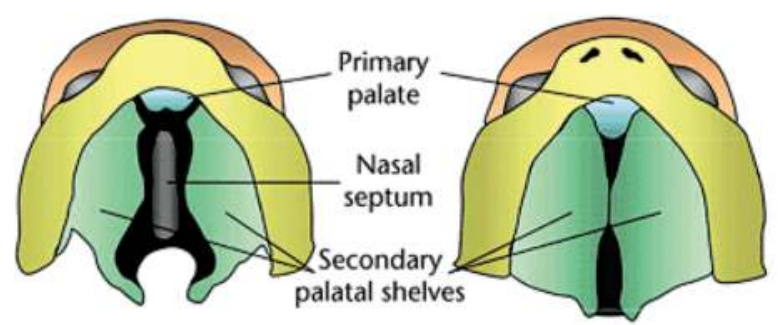

(d)

(e)

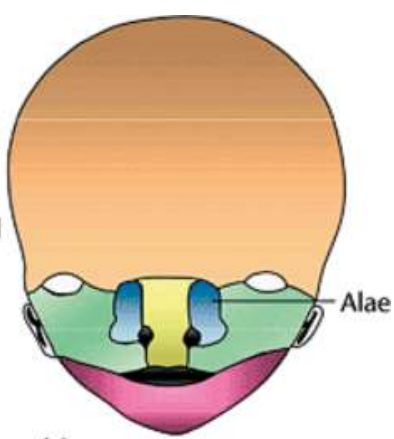

(c)

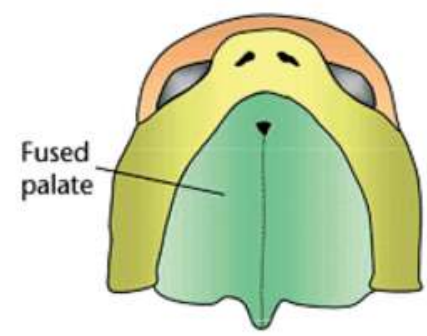

(f)

Figure 1. Schematic diagrams depicting human craniofacial development and formation of the secondary palate [12]. (a) By the fourth week of embryonic development, neural crest cells have migrated into the craniofacial region to form the frontonasal prominence, paired maxillary processes and the paired mandibular processes. (b) Formation of the nasal pits by the fifth week of embryogenesis divides the frontonasal prominence into paired medial and lateral nasal processes. (c) By the end of the sixth week of embryonic development, the medial nasal processes have merged with one another and with the maxillary processes to form the upper lip and primary palate, whereas the lateral nasal processes form the alae of the nose. The mandibular processes fuse together to form the lower jaw. (d) The secondary palate develops from the maxillary processes as bilateral outgrowths which grow vertically down the side of the tongue during the sixth week of embryogenesis. (e) During the seventh week of embryonic development, the palatal shelves elevate to a horizontal position above the tongue, make contact with one another and begin to fuse. (f) Fusion of the secondary palatal shelves with one another and with the primary palate and nasal septum is completed by the tenth week of embryogenesis. Figure is adapted from [12] ( ) (2009) John Wiley and Sons Ltd.

\section{Genetics}

Both genetic and environmental factors have been shown to influence the risk of CL/P and CPO. Approximately $70 \%$ of all cases of CL/P and $50 \%$ of cases of $\mathrm{CPO}$ are designated as nonsyndromic [17], with the rest comprised of a wide range of malformation syndromes with known genetic and/or cellular etiologies. A summary of syndromic forms of CL/O and CPO in which the underlying genetic mutation has been elucidated is provided by Dixon et al. (Table 1; see original article for references) [18]. 


\begin{tabular}{|c|c|c|}
\hline Cleft type & Syndrome & Gene \\
\hline \multirow[t]{18}{*}{ Cleft lip $+/-$ cleft palate } & $\begin{array}{l}\text { Autosomal dominant developmental malformations, } \\
\text { deafness, and dystonia }\end{array}$ & $A C T B$ \\
\hline & Familial gastric cancer and CLP & $\mathrm{CDH1}$ \\
\hline & Craniofrontonasal & EFNB1 \\
\hline & Roberts & ESCO2 \\
\hline & Holoprosencephaly & GLI2 \\
\hline & "Oro-facial-digital" & GLI3 \\
\hline & Hydrolethalus & HYLS1 \\
\hline & Van der Woude/popliteal pterygium & IRF6 \\
\hline & $\mathrm{X}$-linked mental retardation and $\mathrm{CL} / \mathrm{P}$ & PHF8 \\
\hline & Gorlin & PTCH1 \\
\hline & CLP-ectodermal dysplasia & PVRL1 \\
\hline & Holoprosencephaly & SHH \\
\hline & Holoprosencephaly & SIX3 \\
\hline & Branchio-oculo-facial & TFAP2A \\
\hline & Holoprosencephaly & TGIF \\
\hline & Ectrodactyly-ectodermal dysplasia-clefting & TP73L \\
\hline & Ankyloblepharon-ectodermal dysplasia-clefting & TP73L \\
\hline & Tetra-amelia with CLP & WNT3 \\
\hline \multirow[t]{16}{*}{ Cleft palate only } & Oculofaciocardiodental & $B C O R$ \\
\hline & CHARGE & CHD7 \\
\hline & Lethal and Escobar multiple pterygium & CHRNG \\
\hline & Stickler type 1 & COL2A1 \\
\hline & Stickler type 2 & COL11A1 \\
\hline & Stickler type 3 & COL11A2 \\
\hline & Desmosterolosis & DHCR24 \\
\hline & Smith-Lemli-Opitz & DHCR7 \\
\hline & Miller & DHODH \\
\hline & Craniofrontonasal & EFNB1 \\
\hline & Kallmann & FGFR1 \\
\hline & Crouzon & FGFR2 \\
\hline & Apert & FGFR2 \\
\hline & Otopalatodigital types 1 and 2 & FLNA \\
\hline & Larsen syndrome; atelosteogenesis & FLNB \\
\hline & Hereditary lymphedema-distichiasis & FOXC2 \\
\hline
\end{tabular}




\begin{tabular}{|c|c|c|}
\hline Cleft type & Syndrome & Gene \\
\hline & Bamforth-Lazarus & FOXE1 \\
\hline & “Oro-facial-digital" & GLI3 \\
\hline & Van der Woude/popliteal pterygium & IRF6 \\
\hline & Andersen & KCNJ2 \\
\hline & Kabuki & $M L L 2$ \\
\hline & Cornelia de Lange & NIPBL \\
\hline & X-linked mental retardation & PQBP1 \\
\hline & Isolated cleft palate & SATB2 \\
\hline & Diastrophic dysplasia & SLC26A2 \\
\hline & Campomelic dysplasia & SOX9 \\
\hline & Pierre Robin & SOX9 \\
\hline & DiGeorge & TBX1 \\
\hline & X-linked cleft palate and ankyloglossia & $T B X 22$ \\
\hline & Treacher Collins & TCOF1 \\
\hline & Loeys-Dietz & TGFBR1 \\
\hline & Loeys-Dietz & TGFBR2 \\
\hline & Saethre-Chotzen & TWIST1 \\
\hline \multirow[t]{2}{*}{ Midline cleft lip } & Opitz G/BBB & MID1 \\
\hline & Oro-facial-digital type I & OFD1 \\
\hline
\end{tabular}

Table 1. Clefting syndromes in which the mutated gene has been identified. Adapted from Ref. [18].

In contrast, nonsyndromic CL/P is complex and multifactorial in origin. Both genetic and environmental risk factors have been shown to influence the probability of occurrence. Furthermore, there is evidence that the presence of environmental factors-in particular, maternal smoking-modulates the risk conferred by genetic factors and vice-versa, complicating the genetic analysis of nonsyndromic forms of CLP [19]. As such, multifactorial models of inheritance which allow for the evaluation of these risk factors both independently and in interaction with each other are preferred.

Association studies such as candidate gene studies, which test correlation between a phenotype and prespecified genes of interest, and genome-wide association studies (GWAS), which identify genetic variations across entire genomes that are associated with a phenotype, have been used to evaluate a variety of genetic polymorphisms associated with nonsyndromic OFC. Genes that have been examined through these studies for associations with nonsyndromic OFC exhibit a range of functions, including growth, DNA transcription, nutrient metabolism, immunity, and oncogenesis. A few such genes are described here. 


\subsection{Growth factors}

Transforming growth factor alpha (TGF- $\alpha$ ) is a growth factor encoded by the TGFA gene that serves as a ligand for the epidermal growth factor receptor, which is involved in cell proliferation, differentiation, and development [20]. The first association study of genes associated with CL/P found an association with TFGA [21]; however, evidence of this linkage since then has been mixed $[22,23]$. TGFA is currently viewed as a modifier, rather than a necessary or sufficient determinant, of risk for OFC.

Proteins in the transforming growth factor beta (TGF- $\beta$ ) family bind various TGF- $\beta$ receptors leading to recruitment and activation of the SMAD family of transcription factors. TGF- $\beta$ is involved in processes including apoptosis, modulation of immune cell function, and wound healing; disruption of TGF- $\beta$ has been implicated in cancer, Loeys-Dietz syndrome, and other conditions [20]. Knockout experiences in mice have shown the TGFB3 gene to be associated with OFC [24, 25], and subsequent association studies have identified these results in humans [26].

\subsection{Transcription factors}

The MSX1 gene, which is a part of the homeobox gene family, codes for a protein that is involved in transcriptional regulation during embryogenesis as well as limb pattern formation, craniofacial development (in particular odontogenesis), and tumor growth inhibition [20]. This gene has been implicated in the development of cleft in several candidate gene studies, and may even account for $1-2 \%$ of all isolated cases of OFC [27].

Interferon regulatory factor 6 (IRF6) is a transcription factor protein that is involved in early development, especially of tissue in the head and face [20]. Mutations of the IRF6 gene at 1q32 causes Van der Woude syndrome, a Mendelian-inherited disorder which induces CL/P or CPO and accounts for about $2 \%$ of all CL/P cases $[28,29]$. The overlap between phenotypic presentation of Van der Woude syndrome and isolated CL/P motivated further study into the role of IRF6 in development of OFC. Variation at IRF6 has been found to be strongly associated with $\mathrm{CL} / \mathrm{P}$ and may account for up to $12 \%$ of the genetic contribution to $\mathrm{CL} / \mathrm{P}$ at the population level [30-32]. Furthermore, the discovery of ILF6 as a risk factor for CL/P served as an important example of elucidating genetic variants associated with cases of nonsyndromic $\mathrm{OFC}$, which are often excluded from genetic analyses [33].

\subsection{Nutrient metabolism}

Deficient maternal folate intake has long been implicated in risk of OFC in children, leading to suggestions that mutations of the enzyme 5,10-methyltetranhydrofolate reductase (MTHFR), which catalyzes the synthesis of 5-methylenetetrahydrofolate, play a role in the etiology of cases of nonsyndromic CL/P [34]. However, results from several association studies evaluating the role of MTHFR mutations in CL/P have been conflicting [35-37].

Retinoic acid plays an important role during development. Its functions, mediated by retinoic acid receptor alpha (RAR- $\alpha)$, include regulation of development, differentiation, apoptosis, granulopoeisis, as well as transcription of genes involved in the circadian 
rhythm [20]. Transgenic and knockout mice studies have additionally proposed a role in facial development [38]. Mutations of the RARA gene have been associated with development of OFC [39].

\section{Epigenetics}

Due to the relative lack of success in identifying causal genetic factors involved in OFC despite the numerous association studies that have been performed, recent attention has been directed toward the role of epigenetic programming, or modifications that do not involve DNA sequencing. Commonly studied epigenetic events include histone modification, chromatin remodeling, posttranscriptional gene alteration via noncoding MicroRNAs, and DNA methylation. MicroRNAs and DNA methylation, in particular, have begun to demonstrate distinct roles in etiologies of OFC.

\subsection{MicroRNAs}

While protein-coding genes make up only about $1.2 \%$ of the human genome, recent estimates suggest that up to $93 \%$ of the human genome codes for RNA transcripts. MicroRNAs (miRNAs) represent the largest family of such noncoding RNAs in the human genome. They are involved in gene silencing and play important roles in cell and tissue differentiation, including development of the secondary palate [40-43]. miRNAs have been shown to orchestrate many of the processes that are central to palatal morphogenesis, including epithelial-mesenchymal transformation, platelet-derived growth factor (PDGF) and TGF- $\beta$ signaling, cell migration and proliferation, and collagen synthesis [44-48]. As such, further analysis of miRNA expression and gene networks will be key to elucidating mechanisms of palatal development as well as etiologies of OFC.

\subsection{DNA methylation}

DNA methylation, one of the most important epigenetic modifications in mammalian cells, is a process by which methyl groups are added to DNA in order to regulate gene expression. Methylation generally occurs at cytosines within the context of symmetrical CpG dinucleotide sequences, which are often concentrated in regions known as $C p G$ islands and found in both gene bodies and promoter regions $[49,50]$. Classically, methylation of $C p G$ islands at gene promoters is thought to induce silencing of gene transcription; however, positive correlation between gene body methylation and gene expression has been observed [51, 52].

DNA methylation was first identified as a potential mediator of palatal development after a series of studies in which DNA demethylating agents were used to induce cleft palate in mice [53-55]. Since then, failures in DNA methylation demonstrated involvement in craniofacial malformations including cleft palate [56,57]. Despite the current lack of knowledge regarding the epigenetic mechanisms mediating palatal development, evidence strongly indicates that DNA methylation plays a central role in regulating this process, and may perhaps serve as future risk assessment and therapeutic targets for patients with OFC. 


\section{Risk factors}

The role of environmental factors in the etiology of OFC has been extensively studied. Known and suspected risk factors for CL/P and CP include family history, maternal nutrition, and exposure to teratogenic agents. The upper lip and palate are developed by 7 and 9 weeks after conception, respectively. Therefore, risk factors must be present before these times to influence the risk of CL/P and CPO.

\subsection{Heredity}

Family history is one of the strongest risk factors for both $\mathrm{CL} / \mathrm{P}$ and $\mathrm{CP}$. The risk of $\mathrm{CL} / \mathrm{P}$ and $\mathrm{CP}$ has been reported to be increased in the first-, second-, and third-degree relatives and the identical twins of individuals with $\mathrm{CL} / \mathrm{P}$ and $\mathrm{CP}$, with even nonsyndromic cases of $\mathrm{CL} / \mathrm{P}$ exhibiting evidence of genetic components [58-61]. However, few cases demonstrate true Mendelian inheritance patterns [62]. Moreover, CL/P and CP are known to be influenced by environmental risk factors. Specifically, there is growing evidence of gene-environment interactions that may influence the risk of these conditions.

\subsection{Maternal drug use}

Maternal drug use seems to play only a small role for the origin of orofacial clefts, but studies have shown that maternal use of folate antagonists (valproic acid and carbamazepine), dihydrofolate reductase inhibitors (trimethoprim, triamterene, and sulfasalazine), benzodiazepines, nonsteroidal anti-inflammatory drugs, retinoids, and corticosteroids is associated with a marked increase of cleft lip and palate [63-67].

\subsection{Maternal diseases}

The increased risk of having a child with $\mathrm{CL} / \mathrm{P}$ or $\mathrm{CP}$ in women with nongestational diabetes or maternal hyperthermia is well-characterized [68, 69]. Additionally, a study conducted in Hungary found an increased risk of CL/P for children born to mothers with influenza, common cold, orofacial herpes, and gastroenteritis during pregnancy, posterior $\mathrm{CP}$ in mothers with influenza, sinusitis, and bronchitis, and OFC in mothers with epilepsy or angina pectoris [70].

\subsection{Nutrition}

The role of maternal nutrient intake in the development of congenital malformations in the child has long been studied with the aim of elucidating the etiologies of specific birth defects and informing effective prevention strategies. Evidence indicates that maternal nutrient intake affects the risk of giving birth to a child with CL/P or CP. In particular, a lack of vitamin B9, more commonly known as folate (or its synthetic form, folic acid), in the mother's diet has long been linked to the risk of congenital malformations. An association between maternal 
folate intake and reduced risk of having a child with CL/P or CP has previously been demonstrated [71]. However, studies have not consistently linked folic acid with OFC as they have with neural tube defects $[72,73]$.

Previous reports have shown maternal intake of vitamins other than folate, such as other B vitamins (e.g. riboflavin), iron, zinc, and the amino acids choline, methionine, and cysteine, to be associated with reduced risk of having a child with CL/P or CP $[72,74,75]$.

Vitamin A is known to play a crucial role in fetal development. Deficient and excessive intakes of vitamin A increase the risk of birth defects, including OFC, in animals as well as humans [76-79], but exact daily intake numbers have not been established [80].

\subsection{Maternal exogenous exposures}

Most of the CL/P and CPO epidemiologic studies support a role for environmental factors in the etiology of clefting. The most common risk factors reported were maternal exposure to tobacco products [81, 82], alcohols [83], some viral infections [70], pesticides [84], and teratogens in the workplace or at home in early pregnancy [85-87]. Recognized teratogens included rare exposures such as phenytoin, valproic acid, thalidomide, and herbicides such as dioxin. As mentioned previously, risk of CL/P or CPO conferred by these exposures-in particular tobacco-may be modulated by the presence or absence of certain genetic factors [19, 88, 89].

\section{Cleft palate and cancer}

Several studies from different countries (USA, Latvia, Denmark, and Brazil) have identified an association between cleft palate and cancer [90-95]. The first epidemiological studies addressed the presence of cancer in cleft lip/palate subjects and their families. Parents of kids with sporadic CL/P have a higher risk of developing cancer than control families [96], and increased risk of cancer in adulthood can be seen in a Danish population-based cohort of $\mathrm{CL} / \mathrm{P}$ subjects [97]. Such studies suggested that the association was most frequent for breast cancer but also colorectal, gastric, prostate, and uterus cancers. In a large study, 313 families segregating cases of isolated $\mathrm{CL} / \mathrm{P}$, including information of 13,879 individuals, were analyzed by Vieira [93]. The study brings further evidence that individuals born with CL/P and their family members have a higher prevalence of cancer than the general population. This risk is three times higher in first- and second-degree relatives and decreases to 1.5 times in third-degree relatives.

A possible genetic link was identified in two families with mutations in the E-cadherin gene $\mathrm{CDH} 1$ with CL/P and hereditary diffuse gastric cancer [98]. CDH1 is highly expressed in the palate. Vogelaar et al. also identified germline mutations multiple families with gastric cancer and orofacial clefts [99]. One concern in interpreting these studies is that cleft lip/palate patients tend to have a higher prevalence of behavioral risk factors, such as smoking and drinking because of their limited social interactions as adolescents, thus 
are at higher risk of tobacco and alcohol-related cancers independently from their initial malformation.

What is lacking is a study of cancer cases and the risk of cleft palate in their family members. Such studies are limited by the fact that the genetic defect is still a rare event, and the number of cancer cases necessary to address the problem would be extremely large. A study conducted on family members of cancer patients (Taioli et al. [95]) involved an epidemiological questionnaire including family history of cancer and congenital oral cleft malformations that was administered to 168 cancer survivors and a population-based sample of 170 healthy subjects. In the control group, $1.2 \%$ reported a family member with $\mathrm{CL} / \mathrm{P}$; among cancer survivors, the figure was $4.2 \%$ (odds ratio: $3.7 ; 95 \%$ confidence interval: $0.75-17.8 ; p=.07$ ). Among cancer survivors with a family member with $\mathrm{CL} / \mathrm{P}$, there was an apparent excess of testicular cancer and melanoma in comparison with the cancer survivors with no family history of $\mathrm{CL} / \mathrm{P}$. These preliminary results suggest a common etiologic background for cancer and CL/P.

Taken all together, the data suggest that there are shared environmental and genetic factors in families that predispose to both cleft palate and cancer.

\section{Conclusion}

OFCs are the most common craniofacial anomalies, and one of the most common congenital anomalies worldwide. OFCs have historically been grouped as CL/P or CPO. However, existing evidence suggests that separate etiologies may exist for cleft lip alone versus cleft lip with palate. $\mathrm{CL} / \mathrm{P}$ and $\mathrm{CPO}$ are classified as syndromic or nonsyndromic; nonsyndromic cases are further subclassified as multiple or isolated.

Both genetic and environmental factors have been implicated in the etiology of OFC. The genes underlying a number of known syndromes associated with OFC have been identified. Furthermore, environmental factors such as alcohol and tobacco have been shown to modulate the risk of OFC conferred by certain genetic factors.

Although nonsyndromic OFCs are not traditionally the subject of genetic analysis, a number of genomic association studies have evaluated the link between genetic variants and nonsyndromic OFC. Examples of genes that have been examined in such studies include those that code for growth factors, transcription factors, and nutrient metabolism proteins. In addition to genetic factors, studies have recently begun to explore the role of epigenetic modifications in palatal ontogeny and etiology of OFC.

A number of environmental and maternal factors that influence the risk of having a child with OFC are well-described. In particular, family history, maternal drug use, nutrition, and exogenous exposures demonstrate strong links with development of OFC in the child.

Several studies have shown a higher incidence of cancer amongst patients with CL/P and their families. Additionally, studies have begun to identify higher rates of CL/P in the families of patients with cancer, although less is known about this. Combined, these suggest that CL/P and cancer may be mediated by shared environmental and genetic etiologies. 


\section{Author details}

Mairaj K. Ahmed ${ }^{1 *}$, Anthony H. Bui ${ }^{2}$ and Emanuela Taioli ${ }^{3}$

*Address all correspondence to: mairaj.ahmed@mountsinai.org

1 Cleft/Craniofacial Center, Icahn School of Medicine at Mount Sinai, NY, NY, USA

2 Icahn School of Medicine at Mount Sinai, NY, NY, USA

3 Institute for Translational Epidemiology, Icahn School of Medicine at Mount Sinai, NY, NY, USA

\section{References}

[1] Mossey PA, Modell B. Epidemiology of oral clefts 2012: an international perspective. Front Oral Biol 2012;16:1-18. doi:10.1159/000337464

[2] Gorlin RJ, Cohen MM, Hennekam RCM. Syndromes of the Head and Neck. New York: Oxford University Press; 2001.

[3] Mossey PA, Castilla EE. Global Registry and Database on Craniofacial Anomalies: Report of a WHO Registry Meeting on Craniofacial Anomalies. Geneva, Switzerland: World Health Organization; 2001.

[4] Allam E, Windsor L, Stone C. Cleft lip and palate: etiology, epidemiology, preventive and intervention strategies. Anat Physiol 2014;4:940-2161. doi:10.4172/2161-0940.1000150

[5] Forrester MB, Merz RD. Descriptive epidemiology of oral clefts in a multiethnic population, Hawaii, 1986-2000. Cleft Palate-Craniofacial J 2004;41:622-8. doi:10.1597/03-089.1

[6] Christensen K, Holm NV, Olsen J, Kock K, Fogh-Andersen P. Selection bias in geneticepidemiological studies of cleft lip and palate. Am J Hum Genet 1992;51:654-9.

[7] Mastroiacovo P, Maraschini A, Leoncini E, Mossey P, Bower C, Castilla EE, et al. Prevalence at birth of cleft lip with or without cleft palate: data from the International Perinatal Database of Typical Oral Clefts (IPDTOC). Cleft Palate-Craniofacial J 2011;48:66-81. doi:10.1597/09-217

[8] Venkatesh R Syndromes and anomalies associated with cleft. Indian J Plast Surg 2009;42 Suppl:S51-5. doi:10.4103/0970-0358.57187

[9] Shaw GM, Carmichael SL, Yang W, Harris JA, Lammer EJ. Congenital malformations in births with orofacial clefts among 3.6 million California births, 1983-1997. Am J Med Genet A 2004;125A:250-6. doi:10.1002/ajmg.a.20508

[10] Wyszynski DF, Sarkozi A, Czeizel AE. Oral clefts with associated anomalies: methodological issues. Cleft Palate-Craniofacial J 2006;43:1-6. doi:10.1597/04-085R2.1

[11] Bronner ME, LeDouarin NM. Development and evolution of the neural crest: an overview. Dev Biol 2012;366:2-9. doi:10.1016/j.ydbio.2011.12.042 
[12] Thomason HA, Dixon MJ, Thomason HA, Dixon MJ. Craniofacial defects and cleft lip and palate. Encycl Life Sci Chichester, UK: John Wiley \& Sons, Ltd.; 2009. doi:10.1002/9780470015902.a0020915

[13] Fogh-Andersen P Inheritance of harelip and cleft palate: contribution to the elucidation of the etiology of the congenital clefts of the face. J Am Med Assoc 1947;133:276. doi:10.1001/jama.1947.02880040062031

[14] Fraser FC. Thoughts on the etiology of clefts of the palate and lip. Acta Genet Stat Med 1955;5:358-69.

[15] Harville EW, Wilcox AJ, Lie RT, Vindenes H, Åbyholm F. Cleft lip and palate versus cleft lip only: are they distinct defects? Am J Epidemiol 2005;162:448-53. doi:10.1093/aje/ kwi214

[16] Weinberg SM, Brandon CA, McHenry TH, Neiswanger K, Deleyiannis FWB, De Salamanca JE, et al. Rethinking isolated cleft palate: evidence of occult lip defects in a subset of cases. Am J Med Genet Part A 2008;146:1670-5. doi:10.1002/ajmg.a.32291

[17] Jones MC. Etiology of facial clefts: prospective evaluation of 428 patients. Cleft Palate J 1988;25:16-20.

[18] Dixon MJ, Marazita ML, Beaty TH, Murray JC. Cleft lip and palate. Synthesizing genetic and environmental influences. Natl Inst Heal 2011;12:167-78. doi:10.1038/nrg2933.Cleft

[19] Beaty TH, Ruczinski I, Murray JC, Marazita ML, Munger RG, Hetmanski JB, et al. Evidence for gene-environment interaction in a genome wide study of isolated, non-syndromic cleft palate. Genet Epidemiol 2011;35:469-78. doi:10.1002/gepi.20595.Evidence

[20] The NCBI handbook [Internet]. Bethesda (MD): National Library of Medicine (US), National Center for Biotechnology Information; 2002 Oct. Chapter 18, The Reference Sequence (RefSeq) Project. Available from http://www.ncbi.nlm.nih.gov/books/NBK21091.

[21] Ardinger HH, Buetow KH, Bell GI, Bardach J, VanDemark DR, Murray JC. Association of genetic variation of the transforming growth factor-alpha gene with cleft lip and palate. Am J Hum Genet 1989;45:348-53.

[22] Jugessur A, Lie RT, Wilcox AJ, Murray JC, Taylor JA, Saugstad OD, et al. Variants of developmental genes (TGFA, TGFB3, and MSX1) and their associations with orofacial clefts: a case-parent triad analysis. Genet Epidemiol 2003;24:230-9. doi:10.1002/gepi.10223

[23] Mitchell LE. Transforming growth factor alpha locus and nonsyndromic cleft lip with or without cleft palate: a reappraisal. Genet Epidemiol 1997;14:231-40. doi:10.1002/ (SICI)1098-2272(1997)14:3<231::AID-GEPI2>3.0.CO;2-8

[24] Proetzel G, Pawlowski SA, Wiles MV, Yin M, Boivin GP, Howles PN, et al. Transforming growth factor-beta 3 is required for secondary palate fusion. Nat Genet 1995;11:409-14. doi:10.1038/ng1295-409 
[25] Kaartinen V, Voncken JW, Shuler C, Warburton D, Bu D, Heisterkamp N, et al. Abnormal lung development and cleft palate in mice lacking TGF-beta 3 indicates defects of epithelial-mesenchymal interaction. Nat Genet 1995;11:415-21. doi:10.1038/ng1295-415

[26] Marazita ML, Murray JC, Lidral AC, Arcos-Burgos M, Cooper ME, Goldstein T, et al. Meta-analysis of 13 genome scans reveals multiple cleft lip/palate genes with novel loci on 9q21 and 2q32-35. Am J Hum Genet 2004;75:161-73. doi:10.1086/422475

[27] Jezewski PA, Vieira AR, Nishimura C, Ludwig B, Johnson M, O’Brien SE, et al. Complete sequencing shows a role for MSX1 in non-syndromic cleft lip and palate. J Med Genet 2003;40:399-407. doi:10.1136/jmg.40.6.399

[28] Rintala AE, Ranta R. Lower lip sinuses: I. Epidemiology, microforms and transverse sulci. Br J Plast Surg 1981;34:26-30.

[29] Ferrero GB, Baldassarre G, Panza E, Valenzise M, Pippucci T, Mussa A, et al. A heritable cause of cleft lip and palate-Van der Woude syndrome caused by a novel IRF6 mutation. Review of the literature and of the differential diagnosis. Eur J Pediatr 2010;169:223-8. doi:10.1007/s00431-009-1011-3

[30] Zucchero TM, Cooper ME, Maher BS, Daack-Hirsch S, Nepomuceno B, Ribeiro L, et al. Interferon regulatory factor 6 (IRF6) gene variants and the risk of isolated cleft lip or palate. N Engl J Med 2004;351:769-80. doi:10.1056/NEJMoa032909

[31] Houdayer C, Bonaïti-Pellié C, Erguy C, Soupre V, Dondon MG, Bürglen L, et al. Possible relationship between the van der Woude syndrome (vWS) locus and nonsyndromic cleft lip with or without cleft palate (NSCL/P). Am J Med Genet 2001;104:86-92.

[32] Lidral AC, Moreno LM. Progress toward discerning the genetics of cleft lip. Curr Opin Pediatr 2005;17:731-9. doi:10.1097/01.mop.0000185138.65820.7f

[33] Stanier P, Moore GE. Genetics of cleft lip and palate: syndromic genes contribute to the incidence of non-syndromic clefts. Hum Mol Genet 2004;13Spec No:R73-81. doi:10.1093/ hmg/ddh052

[34] Martinelli M, Scapoli L, Pezzetti F, Carinci F, Carinci P, Stabellini G, et al. C677T variant form at the MTHFR gene and CL/P: a risk factor for mothers? Am J Med Genet 2001;98:357-60. doi:10.1002/1096-8628(20010201)98:4<357::AID-AJMG1108>3.0.CO;2-F

[35] Shaw GM, Rozen R, Finnell RH, Todoroff K, Lammer EJ. Infant C677T mutation in MTHFR, maternal periconceptional vitamin use, and cleft lip. Am J Med Genet 1998;80:196-8. doi:10.1002/(SICI)1096-8628(19981116)80:3<196::AID-AJMG2>3.0.CO;2-V

[36] Blanton SH, Patel S, Hecht JT, Mulliken JB. MTHFR is not a risk factor in the development of isolated nonsyndromic cleft lip and palate. Am J Med Genet 2002;110:404-5. doi:10.1002/ajmg.10496

[37] Jugessur A, Wilcox AJ, Lie RT, Murray JC, Taylor JA, Ulvik A, et al. Exploring the effects of methylenetetrahydrofolate reductase gene variants C677T and A1298C on the risk of orofacial clefts in 261 Norwegian case-parent triads. Am J Epidemiol 2003;157:1083-91. 
[38] Lohnes D, Mark M, Mendelsohn C, Dollé P, Dierich A, Gorry P, et al. Function of the retinoic acid receptors (RARs) during development (I). Craniofacial and skeletal abnormalities in RAR double mutants. Development 1994;120:2723-48.

[39] Shaw D, Ray A, Marazita M, Field L. Further evidence of a relationship between the retinoic acid receptor alpha locus and nonsyndromic cleft lip with or without cleft palate (CL+/-P). Am J Hum Genet 1993;53:1156-7.

[40] Conrad R, Barrier M, Ford LP. Role of miRNA and miRNA processing factors in development and disease. Birth Defects Res Part C-Embryo Today Rev 2006;78:107-17. doi:10.1002/bdrc.20068

[41] Hinton A, Hunter S, Reyes G, Fogel GB, King CC. From pluripotency to islets. miRNAs as critical regulators of human cellular differentiation. Adv Genet. 2012;79:1-34. doi:10.1016/B978-0-12-394395-8.00001-3

[42] Pasquinelli AE, Ruvkun G. Control of developmental timing by microRNAs and their targets. Annu Rev Cell Dev Biol 2002;18:495-513. doi:10.1146/annurev. cellbio.18.012502.105832

[43] Mukhopadhyay P, Brock G, Pihur V, Webb C, Pisano MM, Greene RM. Developmental microRNA expression profiling of murine embryonic orofacial tissue. Birth Defects Res A Clin Mol Teratol 2010;88:511-34. doi:10.1002/bdra.20684

[44] Gregory PA, Bracken CP, Bert AG, Goodall GJ. MicroRNAs as regulators of epithelialmesenchymal transition. Cell Cycle 2008;7:3112-7. doi:10.4161/cc.7.20.6851

[45] Eberhart JK, He X, Swartz ME, Yan Y-L, Song H, Boling TC, et al. MicroRNA mirn140 modulates PDGF signaling during palatogenesis. Nat Genet 2008;40:290-8. doi:10.1038/ng.82

[46] Shin J-O, Lee J-M, Cho K-W, Kwak S, Kwon H-J, Lee M-J, et al. MiR-200b is involved in TGF- $\beta$ signaling to regulate mammalian palate development. Histochem Cell Biol 2012;137:67-78. doi:10.1007/s00418-011-0876-1

[47] Shin J-O, Nakagawa E, Kim E-J, Cho K-W, Lee J-M, Cho S-W, et al. miR-200b regulates cell migration via Zeb family during mouse palate development. Histochem Cell Biol 2012;137:459-70. doi:10.1007/s00418-012-0915-6

[48] Li L, Shi JY, Zhu GQ, Shi B. MiR-17-92 cluster regulates cell proliferation and collagen synthesis by targeting TGFB pathway in mouse palatal mesenchymal cells. J Cell Biochem 2012;113:1235-44. doi:10.1002/jcb.23457

[49] Bonasio R, Tu S, Reinberg D. Molecular signals of epigenetic states. Science 2010;330:6126. doi:10.1126/science.1191078

[50] Jones PA, Takai D. The role of DNA methylation in mammalian epigenetics. Science 2001;293:1068-70. doi:10.1126/science.1063852

[51] Ndlovu MN, Denis H, Fuks F. Exposing the DNA methylome iceberg. Trends Biochem Sci 2011;36:381-7. doi:10.1016/j.tibs.2011.03.002 
[52] Jjingo D, Conley AB, Yi S V, Lunyak V V, Jordan IK. On the presence and role of human gene-body DNA methylation. Oncotarget 2012;3:462-74. doi:10.18632/oncotarget.497

[53] Rogers JM, Francis BM, Sulik KK, Alles AJ, Massaro EJ, Zucker RM, et al. Cell death and cell cycle perturbation in the developmental toxicity of the demethylating agent, 5-aza2'-deoxycytidine. Teratology 1994;50:332-9. doi:10.1002/tera.1420500504

[54] Branch S, Chernoff N, Brownie C, Magnus FB. 5-AZA-2'-deoxycytidine-induced dysmorphogenesis in the rat. Teratog Carcinog Mutagen 1999;19:329-38. doi:10.1002/ (SICI)1520-6866(1999)19:5<329::AID-TCM3>3.0.CO;2-S

[55] Bulut HE, Ozdemir O, Başimoglu-Koca Y, Korkmaz M, Atalay A. Effects of a DNA demethylating agent-5-azacytidine-on testicular morphology during mouse embryo development. Okajimas Folia Anat Jpn 1999;76:47-53.

[56] Kuriyama M, Udagawa A, Yoshimoto S, Ichinose M, Sato K, Yamazaki K, et al. DNA methylation changes during cleft palate formation induced by retinoic acid in mice. Cleft Palate-Craniofacial J 2008;45:545-51. doi:10.1597/07-134.1

[57] Seelan RS, Appana SN, Mukhopadhyay P, Warner DR, Brock GN, Pisano MM, et al. Developmental profiles of the murine palatal methylome. Birth Defects Res A Clin Mol Teratol 2013;97:171-86. doi:10.1002/bdra.23126

[58] Mitchell LE, Christensen K. Analysis of the recurrence patterns for nonsyndromic cleft lip with or without cleft palate in the families of 3,073 Danish probands. Am J Med Genet 1996;61:371-6.doi:10.1002/(SICI)1096-8628(19960202)61:4<371::AID-AJMG12>3.0.CO;2-P

[59] Grosen D, Chevrier C, Skytthe A, Bille C, Mølsted K, Sivertsen A, et al. A cohort study of recurrence patterns among more than 54,000 relatives of oral cleft cases in Denmark: support for the multifactorial threshold model of inheritance. J Med Genet 2010;47:1628. doi:10.1136/jmg.2009.069385

[60] Grosen D, Bille C, Petersen I, Skytthe A, Hjelmborg JvB, Pedersen JK, et al. Risk of oral clefts in twins. Epidemiology 2011;22:313-9. doi:10.1097/EDE.0b013e3182125f9c

[61] Christensen K, Mitchell LE. Familial recurrence-pattern analysis of nonsyndromic isolated cleft palate-a Danish Registry study. Am J Hum Genet 1996;58:182-90.

[62] Jugessur A, Shi M, Gjessing HK, Lie RT, Wilcox AJ, Weinberg CR, et al. Genetic determinants of facial clefting: analysis of 357 candidate genes using two national cleft studies from Scandinavia. PLoS One 2009;4:e5385. doi:10.1371/journal.pone.0005385

[63] Hernández-Díaz S, Werler MM, Walker AM, Mitchell AA. Folic acid antagonists during pregnancy and the risk of birth defects. N Engl J Med 2000;343:1608-14. doi:10.1056/ NEJM200011303432204

[64] Dolovich LR, Addis A, Vaillancourt JM, Power JD, Koren G, Einarson TR. Benzodiazepine use in pregnancy and major malformations or oral cleft: meta-analysis of cohort and case-control studies. BMJ 1998;317:839-43. 
[65] Lammer EJ, Chen DT, Hoar RM, Agnish ND, Benke PJ, Braun JT, et al. Retinoic acid embryopathy. N Engl J Med 1985;313:837-41. doi:10.1056/NEJM198510033131401

[66] Hernandez RK, Werler MM, Romitti P, Sun L, Anderka M, National Birth Defects Prevention Study. Nonsteroidal antiinflammatory drug use among women and the risk of birth defects. Am J Obstet Gynecol 2012;206:228.e1-8. doi:10.1016/j.ajog.2011.11.019

[67] Carmichael SL, Shaw GM, Ma C, Werler MM, Rasmussen SA, Lammer EJ, et al. Maternal corticosteroid use and orofacial clefts. Am J Obstet Gynecol 2007;197:585.e1-7; discussion 683-4, e1-7. doi:10.1016/j.ajog.2007.05.046

[68] Aberg A, Westbom L, Källén B. Congenital malformations among infants whose mothers had gestational diabetes or preexisting diabetes. Early Hum Dev 2001;61:85-95.

[69] Hashmi SS, Gallaway MS, Waller DK, Langlois PH, Hecht JT. Maternal fever during early pregnancy and the risk of oral clefts. Birth Defects Res Part A-Clin Mol Teratol 2010;88:186-94. doi:10.1002/bdra.20646

[70] Métneki J, Puhó E, Czeizel AE. Maternal diseases and isolated orofacial clefts in Hungary. Birth Defects Res A Clin Mol Teratol 2005;73:617-23. doi:10.1002/bdra.20177

[71] Wilcox AJ, Lie RT, Solvoll K, Taylor J, McConnaughey DR, Abyholm F, et al. Folic acid supplements and risk of facial clefts: national population based case-control study. BMJ 2007;334:464. doi:10.1136/bmj.39079.618287.0B

[72] Goh YI, Bollano E, Einarson TR, Koren G. Prenatal multivitamin supplementation and rates of congenital anomalies: a meta-analysis. J Obstet Gynaecol Canada JOGC = J D’obstétrique Gynécologie Du Canada JOGC 2006;28:680-9.

[73] Ray JG, Meier C, Vermeulen MJ, Boss S, Wyatt PR, Cole DEC. Association of neural tube defects and folic acid food fortification in Canada. Lancet (London, England) 2002;360:2047-8. doi:10.1016/S0140-6736(02)11994-5

[74] Shaw GM, Carmichael SL, Laurent C, Rasmussen SA. Maternal nutrient intakes and risk of orofacial clefts. Epidemiology 2006;17:285-91. doi:10.1097/01.ede.0000208348.30012.35

[75] Carmichael SL, Yang W, Feldkamp ML, Munger RG, Siega-Riz AM, Botto LD, et al. Reduced risks of neural tube defects and orofacial clefts with higher diet quality. Arch Pediatr Adolesc Med 2012;166:121-6. doi:10.1001/archpediatrics.2011.185

[76] RothmanKJ,MooreLL,SingerMR,NguyenUS,ManninoS,MilunskyA.Teratogenicityofhigh vitamin A intake. N Engl J Med 1995;333:1369-73. doi:10.1097/00006254-199605000-00007

[77] Shaw GM, Wasserman CR, Block G, Lammer EJ. High maternal vitamin A intake and risk of anomalies of structures with a cranial neural crest cell contribution. Lancet (London, England) 1996;347:899-900.

[78] Mills JL, Simpson JL, Cunningham GC, Conley MR, Rhoads GG. Vitamin A and birth defects. Am J Obstet Gynecol 1997;177:31-6. doi:10.1016/S0002-9378(97)70434-4 
[79] Mastroiacovo P, Mazzone T, Addis A, Elephant E, Carlier P, Vial T, et al. High vitamin A intake in early pregnancy and major malformations: a multicenter prospective controlled study. Teratology1999;59:7-11.doi:10.1002/(SICI)1096-9926(199901)59:1<7::AID-TERA4>3.0.CO;2-6

[80] Johansen AMW, Lie RT, Wilcox AJ, Andersen LF, Drevon CA. Maternal dietary intake of vitamin A and risk of orofacial clefts: a population-based case-control study in Norway. Am J Epidemiol 2008;167:1164-70. doi:10.1093/aje/kwn035

[81] Chevrier C, Bahuau M, Perret C, Iovannisci DM, Nelva A, Herman C, et al. Genetic susceptibilities in the association between maternal exposure to tobacco smoke and the risk of nonsyndromic oral cleft. Am J Med Genet Part A 2008;146:2396-406. doi:10.1002/ ajmg.a.32505

[82] Li Z, Liu J, YeR, Zhang L, Zheng X, Ren A. Maternal passive smoking and risk of cleft lip with or without cleft palate. Epidemiology 2010;21:240-2. doi:10.1097/EDE.0b013e3181c9f941

[83] Boyles AL, Deroo LA, Lie RT, Taylor JA, Jugessur A, Murray JC, et al. Maternal alcohol consumption, alcohol metabolism genes, and the risk of oral clefts: a population-based case-control study in Norway, 1996-2001. Am J Epidemiol 2010;172:924-31. doi:10.1093/aje/kwq226

[84] Romitti PA, Herring AM, Dennis LK, Wong-Gibbons DL. Meta-analysis: pesticides and orofacial clefts. Cleft Palate-Craniofacial J 2007;44:358-65. doi:10.1597/06-100.1

[85] Lin S, Herdt-Losavio ML, Chapman BR, Munsie J-P, Olshan AF, Druschel CM. Maternal occupation and the risk of major birth defects: a follow-up analysis from the National Birth Defects Prevention Study. Int J Hyg Environ Health 2013;216:317-23. doi:10.1016/j. ijheh.2012.05.006

[86] Desrosiers TA, Lawson CC, Meyer RE, Richardson DB, Daniels JL, Waters MA, et al. Maternal occupational exposure to organic solvents during early pregnancy and risks of neural tube defects and orofacial clefts. Occup Env Med 2013;69:493-9. doi:10.1136/ oemed-2011-100245.Maternal

[87] Cordier S, Garlantézec R, Labat L, Rouget F, Monfort C, Bonvallot N, et al. Exposure during pregnancy to glycol ethers and chlorinated solvents and the risk of congenital malformations. Epidemiology 2012;23:806-12. doi:10.1097/EDE.0b013e31826c2bd8

[88] Li L, Zhu G, Meng T, Shi J, Wu J, Xu X, et al. Biological and epidemiological evidence of interaction of infant genotypes at Rs7205289 and maternal passive smoking in cleft palate. Am J Med Genet Part A 2011;155:2940-8. doi:10.1002/ajmg.a.34254

[89] Wu T, Fallin MD, Shi M, Ruczinski I, Liang KY, Hetmanski JB, et al. Evidence of geneenvironment interaction for the RUNX2 gene and environmental tobacco smoke in controlling the risk of cleft lip with/without cleft palate. Birth Defects Res A Clin Mol Teratol 2012;94:76-83. doi:10.1002/bdra.22885

[90] Dietz A, Pedersen DA, Jacobsen R, Wehby GL, Murray JC, Christensen K. Risk of breast cancer in families with cleft lip and palate. Ann Epidemiol 2012;22:37-42. doi:10.1016/j. annepidem.2011.09.003 
[91] Steinwachs EF, Amos C, Johnston D, Mulliken J, Stal S, Hecht JT. Nonsyndromic cleft lip and palate is not associated with cancer or other birth defects. Am J Med Genet 2000;90:17-24.

[92] Menezes R, Marazita ML, Goldstein McHenry T, Cooper ME, Bardi K, Brandon C, et al. AXIS inhibition protein 2, orofacial clefts and a family history of cancer. J Am Dent Assoc 2009;140:80-4.

[93] Vieira AR, Khaliq S, Lace B. Risk of cancer in relatives of children born with isolated cleft lip and palate. Am J Med Genet A 2012;158A:1503-4. doi:10.1002/ajmg.a.35359

[94] Lima LS, Silvério MO, Swerts MSO, Aquino SN, Martelli DRB, Martelli-Júnior H. Frequency of cancer in first-degree relatives of patients with cleft lip and/or palate in the Brazilian population. Braz Dent J 2013;24:200-3. doi:10.1590/0103-6440201302191

[95] Taioli E, Ragin C, Robertson L, Linkov F, Thurman NE, Vieira AR. Cleft lip and palate in family members of cancer survivors. Cancer Invest 2010;28:958-62. doi:10.3109/0735 7907.2010.483510

[96] Zhu JL, Basso O, Hasle H, Winther JF, Olsen JH, Olsen J. Do parents of children with congenital malformations have a higher cancer risk? A nationwide study in Denmark. Br J Cancer 2002;87:524-8. doi:10.1038/sj.bjc.6600488

[97] Bille C, Winther JF, Bautz A, Murray JC, Olsen J, Christensen K. Cancer risk in persons with oral cleft - a population-based study of 8,093 cases. Am J Epidemiol 2005;161:104755. doi:10.1093/aje/kwi132

[98] Frebourg T, Oliveira C, Hochain P, Karam R, Manouvrier S, Graziadio C, et al. Cleft lip/ palate and $\mathrm{CDH} 1 / \mathrm{E}$-cadherin mutations in families with hereditary diffuse gastric cancer. J Med Genet 2006;43:138-42. doi:10.1136/jmg.2005.031385

[99] Vogelaar IP, Figueiredo J, van Rooij IALM, Simões-Correia J, van der Post RS, Melo $\mathrm{S}$, et al. Identification of germline mutations in the cancer predisposing gene CDH1 in patients with orofacial clefts. Hum Mol Genet 2013;22:919-26. doi:10.1093/hmg/dds497 